\title{
Experimental and Statistical Study of the Optimization of Fire retardants in a Formulations of Waterborne Intumescent Fire-resistant Coatings for Steel Structure Using Uniform Experimental Design
}

\author{
JIAN Hu, a , CHUNLING Hu ${ }^{2, b}$ \\ ${ }^{1}$ Department of Chemical Engineering, Sichuan Vocational College of Chemical Technology, \\ Luzhou China \\ ${ }^{2}$ Department of Chemical Engineering, Sichuan Vocational College of Chemical Technology, \\ Luzhou China \\ ahujianbox@163.com, bjaneling00@hotmail.com
}

\begin{abstract}
Keywords: waterborne intumescent fire-resistant coatings; steel structure; statistical software; design of experiments; uniform design.

Abstract. This paper presents a uniform design methodology for computer aided experimental design for intumescent fire-resistant coating (IFRC) formulations, exemplifies the benefits of using experimental design together with statistical software to facilitate the optimization of fire retardants in a formulation of an IFRC for structural steelworks. By applying a statistical multivariate design for the screening experiments, many intumescent fire retardants were evaluated in comparatively few experiments. In this work, prior information has been used in the form of a model, based on historical experiments. A uniform design criterion is used to design a few additional experiments so that the resulting model can have an acceptable prediction power. A confirmatory experiment step is shown that a design which uses the uniform design methodology taking advantage of the experimental data collected from the design of experiments that using fewer trials gives a model with equivalent prediction capability. This can be critical where the practical approach which often requires a considerable amount of experimental work and may be costly and time consuming to perform.
\end{abstract}

\section{Introduction}

The protection of metals against fire has become an important issue in the construction industry. Steel, a non-combustible material with good ductility, begins to lose its structural properties above the temperature $773(\mathrm{~K})$ or even as low as $723(\mathrm{~K})$ in case of fire and tends to distort, leading to the collapse of building structures. Usage of intumescent coating is highly recommended as passive fire protection in building construction as it could save precious human lives and assets [1]. Fire-resistant coatings, acting by the phenomena of intumescence, form on heating an expanded multicellular layer, which acts as a thermal shield between the fire and the substrate. It prevents heat from penetrating and flames from spreading. Intumescent coatings are usually composed of three active ingredients: an acid source (generally ammonium polyphosphate-APP), a carbon source (such as pentaerythritol-PER) and a blowing agent (most often melamine-MEL) linked together by a binder[2]. In additional, nano aluminum trihydroxide(Nano-ATH) is used as a new generation of flame-retardant fillers in the formulation.

In order to determine the optimal formulation of above ingredients in IFRC, formulation experimentation usually plays a very important role in the formulation work, there are different methods of design used for experimentation. One approach is to use the traditional "one-factor-at-a-time" (OFAT) method. This involves varying one factor while keeping the others at constant levels. Although simple, this often requires a considerable amount of experimental work and may be costly. Factorial designs of experiments (DOE) are an alternative to the OFAT methodology to design experiments. They have been proven to be more efficient and have many advantages over OFAT, they require less resource (experiments, time, material, etc.) for a given amount of information obtained, this is very important since experiments can be very expensive and time consuming[3]. The most experimental design theories include orthogonal design, D-optimal design and uniform design 
[4]. In this work, the purpose was to perform a Design of Experiments (DOE) to reduce the number of tests needed to obtain the relative influences of formulation variables and key factors on the formulation of a intemuscent fire-retardant coating for structural steelworks.

\section{The preparation of coatings and the effects of the ration of water-borne silicone-acrylate resin on the fire-resisting properties of the coating}

In our prior experiment, APP, MEL, PER, Nano-ATH, $\mathrm{TiO}_{2}$ and eco-friendly silicone-acrylate emulsion and water were mixed by high-speed disperse mixer. The prepared coatings were applied onto the surface of a steel plate (Q235 carbon steel, $15 \mathrm{~cm} \times 7 \mathrm{~cm} \times 6 \mathrm{~mm})$. and dried at room temperature. This process was repeated 10-15 times until the dry film thickness of $3 \pm 0.1 \mathrm{~mm}$ was obtained.

Fire protection test was an examination of heat insulation of flame-retardant coatings. The coated plates were exposed to gas blowlamp flame whose temperature increased in accordance with the standard temperature-time curve (ISO 834 curve) [5]. Three thermocouples were placed on the backside of the test plate and the back temperatures of the plate were recorded. When the average of three back temperatures of the test plate reached $573(\mathrm{~K})$, the time was defined as fire-resisting time. The swelling of intumescent coating is due to the slowly diffusion of the evolved degradation gases released into the degraded matrix. The test took the maximum thickness of intumescent char on the test plate after burning as the thickness of char layer defined as charring height, the experiment data are fed into the origin ${ }^{\circledR} 9.0$ software and the fitted curves plot results are shown in the Fig. 1.
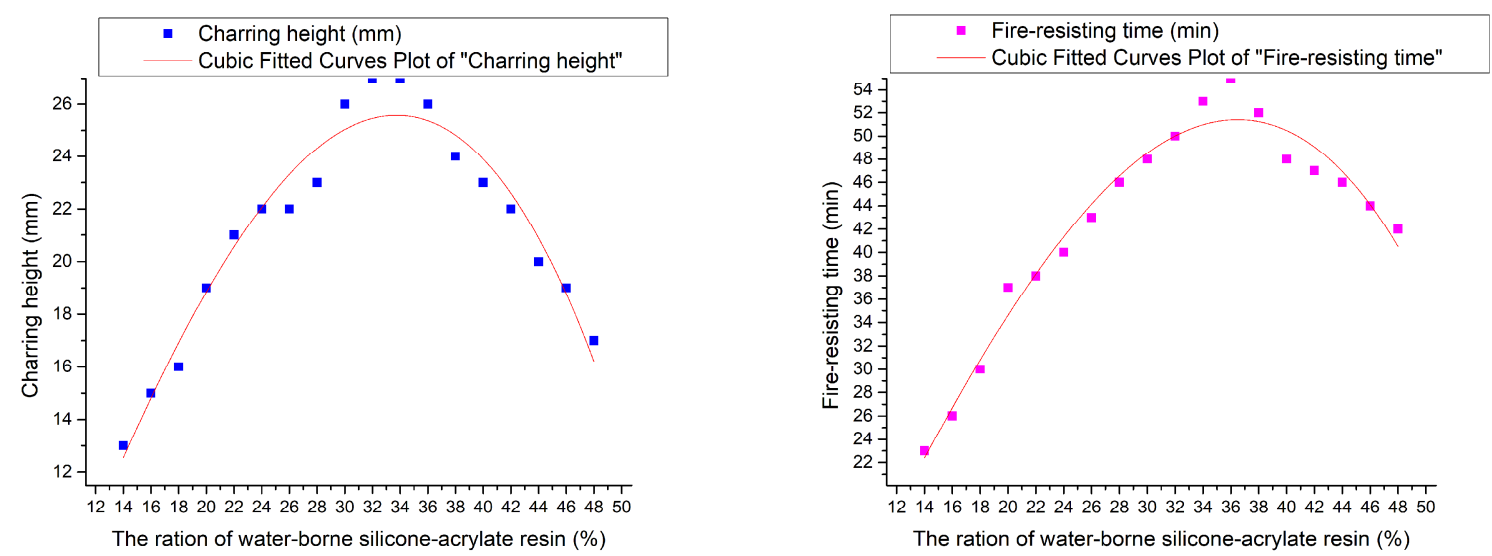

Fig. 1 Effects of the ration of water-borne silicone-acrylate resin on the fire-resisting properties of the coating

\section{Multivariate design of intumescent fire retardants via uniform design of experiments with mixtures}

Experimentation is made to determine the effect of the independent variable (factor) on the dependent variable say response of a process and a relation between them usually illustrated through a regression model by using experimental data. Statistical design of experiment (DOE) is a well known efficient experimentation technique and has been applied in a broad range of fields such as automobile, food, drug, textile, composites and so on industries, to produce high quality products, to operate them more economically, to ensure more stable and reliable process.

There are four interrelated steps in building a DOE[6]: 1) Defining an objective of the study, e.g., better understanding of the system, sorting out important variables, or finding an optimum response. 2)Defining variables that will be manipulated during the experiments (factors) and their levels or ranges of variation. 3)Defining variables that will be measured to describe the outcome of the experimental runs(responses). 4)Choosing one standard design that is compatible with the objective, number of factors, and precision of measurements and has a reasonable cost. The DOE objective is to 
obtain optimal fire protective properties of coatings, Operational factors are related to the protective properties of the coatings.

The studied major influential operational factors were APP(Factor 1), PER (Factor 2), MEL (Factor 3 ), and ATH (Factor 4). The response variable is resisting time of the charring layer, The experimental apparatus of measuring resisting time is shown in Fig. 2. To detect steel substrate temperature, the inner-temperature thermocouple tip was set in the center of the steel I-beam and at half the thickness, thus ensuring good thermal contact of the thermocouple with the steel plate and providing a reliable average temperature of steel along its thickness.

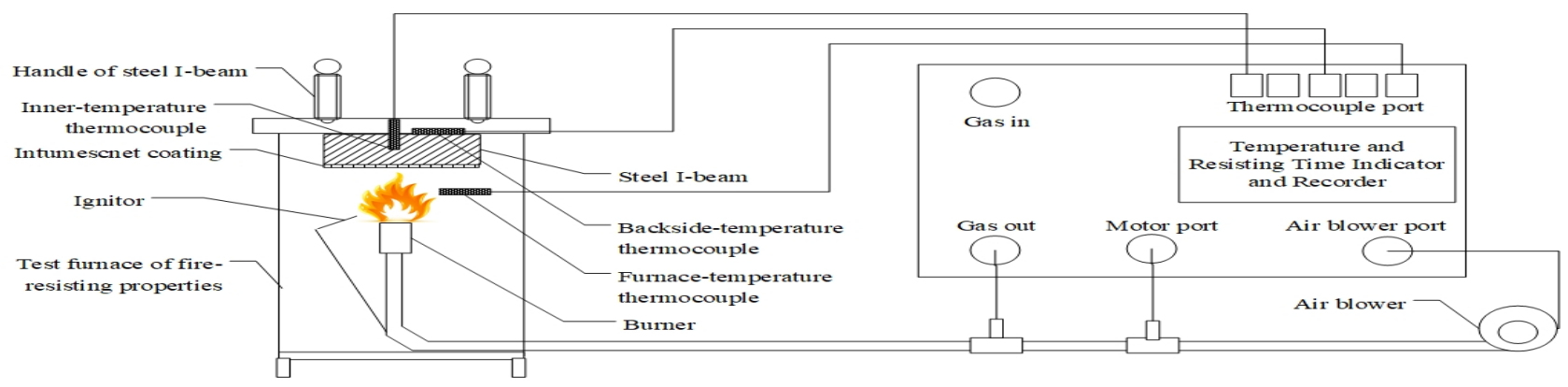

Fig. 2 Equipments apparatus for fire protection test

We chose uniform design [4] as DOE methodology in this multivariate formulation design. A full factorial design was constructed; this design is of resolution IV, which means that the main effects are not confounded with two-factor interactions [3]. We select the unrestricted form of the mixed model and arrange the levels of the factor according uniform design $\mathrm{U}^{*}{ }_{15}\left(15^{7}\right)$ [4], these are shown as in the Table 1.The designs were generated and evaluated by means of Design Expert ${ }^{\circledR}$ 10.0 (Stat-Ease, Inc., USA) software package, fifteen run experiments were performed.

Table 1. Design of experimental project for non-restricted recipe of uniform design $\mathrm{U}_{15}^{*}\left(15^{7}\right)$.

\begin{tabular}{lccccc}
\hline Run & $\begin{array}{c}\text { Factor1 } \\
\text { APP(g) }\end{array}$ & $\begin{array}{c}\text { Factor2 } \\
\text { MEL }(\mathbf{g})\end{array}$ & $\begin{array}{c}\text { Factor3 } \\
\text { PER(g) }\end{array}$ & $\begin{array}{c}\text { Factor4 } \\
\text { ATH }(\mathbf{g})\end{array}$ & $\begin{array}{c}\text { 40\%silicone-acrylate } \\
\text { emulsion }(\mathbf{g})(36 w t \%)\end{array}$ \\
\hline 1 & 1.12 & 16.2 & 68.9 & 13.8 & 138.5 \\
2 & 3.45 & 38.1 & 37 & 21.4 & 138.5 \\
3 & 5.9 & 76.9 & 7.45 & 9.74 & 138.5 \\
4 & 8.48 & 11.4 & 18.7 & 61.4 & 138.5 \\
5 & 11.2 & 30.3 & 1.95 & 56.5 & 138.5 \\
6 & 14.1 & 58.7 & 24.4 & 2.72 & 138.5 \\
7 & 17.2 & 7.21 & 52.9 & 22.7 & 138.5 \\
8 & 20.6 & 23.2 & 28.1 & 28.1 & 138.5 \\
9 & 24.3 & 44.8 & 9.27 & 21.6 & 138.5 \\
10 & 28.4 & 3.67 & 6.79 & 61.1 & 138.5 \\
11 & 33.1 & 16.6 & 48.7 & 1.68 & 138.5 \\
12 & 38.4 & 31.8 & 22.8 & 6.94 & 138.5 \\
13 & 45 & 7.6 & 30.7 & 16.7 & 138.5 \\
14 & 53.6 & 9.48 & 13.5 & 23.4 & 138.5 \\
15 & 67.8 & 3.93 & 2.94 & 25.4 & \\
\hline
\end{tabular}

\section{Response modeling and statistical analysis}

In this case only 15 experiments were needed to estimate the four main effects bi and six first-order interactions between the parameter studied effects $\left(b_{\mathrm{ij}}\right)$ besides the overall mean. The mathematical model used is the following Eq. 1 :

$$
Y=b_{0}+b_{1} X_{1}+\ldots+b_{\mathrm{n}} X_{\mathrm{n}}+b_{12} X_{1} X_{2}+\ldots \ldots+b_{\mathrm{ij}} X_{\mathrm{i}} X_{\mathrm{j}}+\ldots \ldots+b_{\mathrm{hkp}} X_{\mathrm{h}} X_{\mathrm{k}} X_{\mathrm{p}} .
$$

(Y means Resisting time, $X_{\mathrm{i}}$ means Factor's ration, $\mathrm{n}, \mathrm{i}, \mathrm{j}, \mathrm{h}, \mathrm{k}, \mathrm{p}=1 \sim 4$ ) 
Analysis of variance(AVOVA) for quadratic mixture model results are are listed in Table 2. It is obvious from the above results that more than one factor is influencing the output result, and therefore, a statistical analysis was performed. The statistical analysis consisted of finding significant factors for each output response and the model significance according to the ANOVA.

Table 2. ANOVA results table for quadratic mixture model

\begin{tabular}{|c|c|c|c|c|c|c|}
\hline \multicolumn{7}{|c|}{$\begin{array}{l}\text { Response: Fire-resisting time } \\
\text { ANOVA for Quadratic Mixture model }\end{array}$} \\
\hline Source & $\begin{array}{r}\text { Sum of } \\
\text { Squares }\end{array}$ & df & $\begin{array}{r}\text { Mean } \\
\text { Square }\end{array}$ & $\begin{array}{r}\text { F } \\
\text { Value }\end{array}$ & $\begin{array}{r}\text { p-value } \\
\text { Prob }>\text { F }\end{array}$ & \\
\hline Model & 1189.97 & 9 & 132.22 & 28.35 & 0.0009 & significant \\
\hline${ }^{1}$ Linear Mixture & 510.46 & 3 & 170.15 & 36.48 & 0.0008 & \\
\hline$A B$ & 2.86 & 1 & 2.86 & 0.61 & 0.4690 & \\
\hline$A C$ & 156.92 & 1 & 156.92 & 33.64 & 0.0021 & \\
\hline$A D$ & 30.27 & 1 & 30.27 & 6.49 & 0.0514 & \\
\hline$B C$ & 144.35 & 1 & 144.35 & 30.95 & 0.0026 & \\
\hline$B D$ & 149.38 & 1 & 149.38 & 32.03 & 0.0024 & \\
\hline$C D$ & 0.34 & 1 & 0.34 & 0.073 & 0.7974 & \\
\hline Residual & 23.32 & 5 & 4.66 & & & \\
\hline Cor Total & 1213.29 & 14 & & & & \\
\hline
\end{tabular}

${ }^{1}$ Inference for linear mixtures uses Type I sums of squares.

The Model F-value of 28.35 implies the model is significant. There is only a $0.09 \%$ chance that an F-value this large could occur due to noise. Values of Prob $>\mathrm{F}$ less than 0.0500 indicate model terms are significant. In this case $\mathrm{A}(\mathrm{APP}), \mathrm{B}(\mathrm{MEL}), \mathrm{C}(\mathrm{PER}), \mathrm{D}(\mathrm{ATH}), \mathrm{AC}, \mathrm{BC}, \mathrm{BD}$ are significant model terms.

The accuracy of the linear fire-resisting time model for all types of fire retardants can be seen in Fig.3(Left). Fig. 3(Right) shows the fire-resisting time surface responses as a function of all factor content used in the intumescent flame-retardant coatings recipe. As expected, fire-resisting time shows a strong dependence on fire retardants content, whereas is positively influenced by all factors.
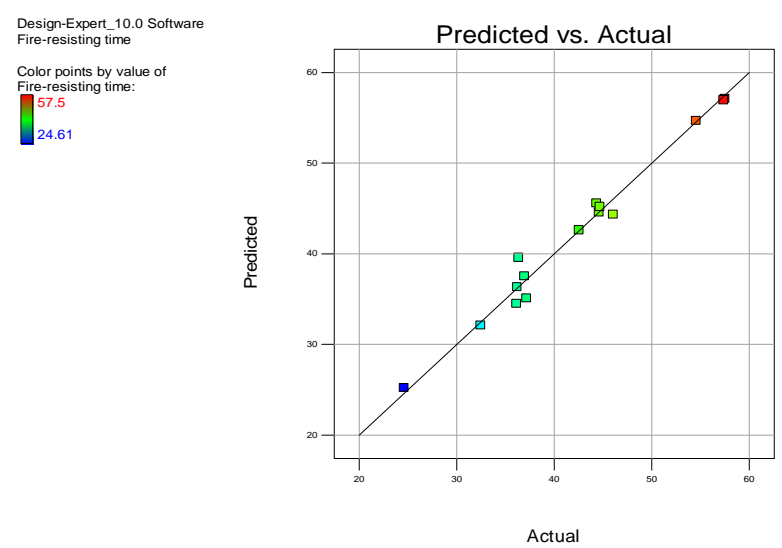
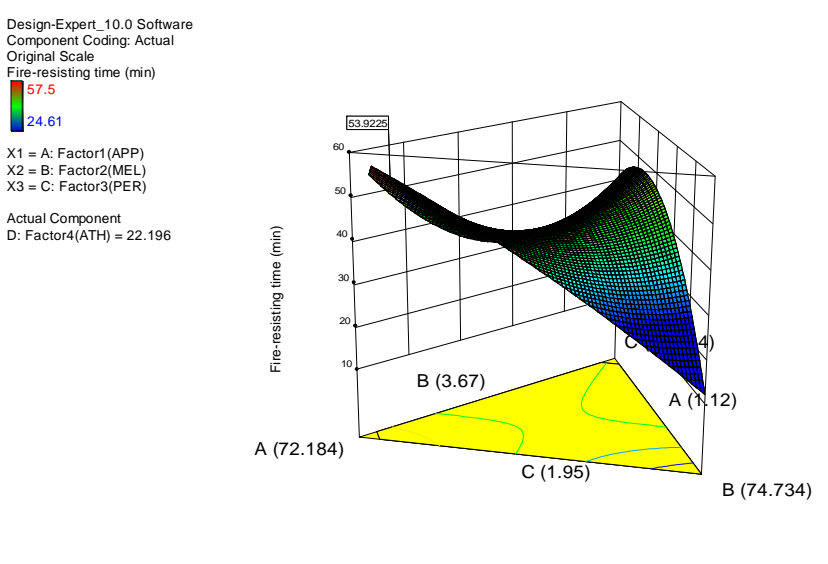

Fig. 3 Comparison of predicted versus actual fire-resisting time(Left) and 3D surface of fire-resisting time response with respect to all factors(Right) 


\section{Prediction and confirmatory experiment}

The application of DOE methodology in this multivariate formulation design has been validated by using a confirmation experiment. The confirmation run 5 times for model validation by setting a numerical optimization to target the fire-resisting time at $60 \mathrm{~min}$ within specification limits of 57 and 62 min according to the combination of factors within software solutions range. Confirmation report indicates that the mean response value is $59.56 \mathrm{~min}$. Compared with the prediction results(Fig. 4), it's indicate that good models were obtained for the responses.
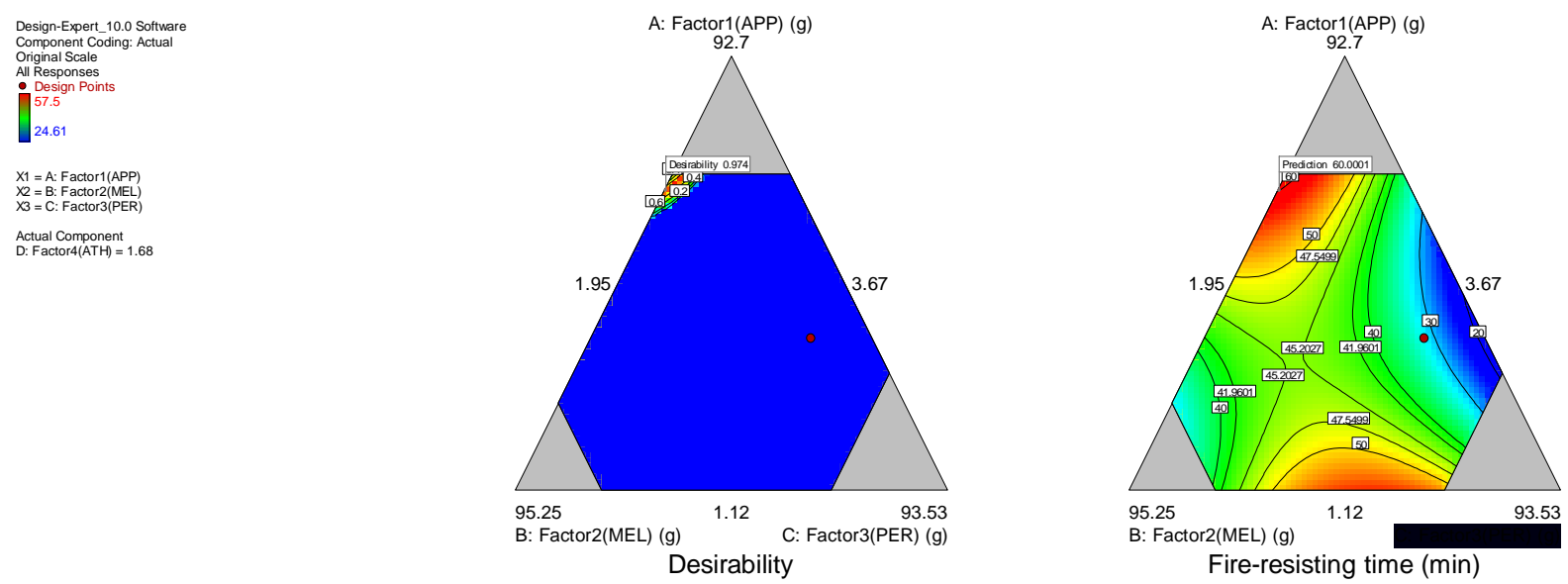

Fig. 4 Graphical optimization of prediction and confirmation

\section{Conclusion}

Experiments involving mixture components of intumescent fire retardants arise frequently in the intumescent fire-retardant coatings for structural steelworks. A statistical experimental design is an effective approach to these problems. However, because of the specialized nature of experimental problems involving mixtures, standard designs such as orthogonal design are often ineffective. We presented an example of multivariate design based on uniform design and illustrated how experimental designs for these problems can be developed. Experimental and statistical software can greatly facilitate the design, execution and subsequent analysis of these experiments. Information that was beneficial to the project was offered by the established relationships between design factors and responses. This design is especially practical when the investigator is faced with large number of factors and is unsure which settings are likely to produce optimal or near optimum responses.

\section{References}

[1] M. Jimenez, S. Duquesne, S. Bourbigot: Thermochim. Acta Vol. 449 (2006),p.16

[2] Guojian Wang, Jiayun Yang:Surf. Progress in Organic Coatings. Vol.70 (2011),p. 150

[3] Douglas C. M: Design and Analysis of Experiments, 7th Edition(John Wiley \& Sons 2009).

[4] Yuan Wang, Kaitai Fang:Uniform design of experiments with mixtures. Science in China Series A(1996)

[5] S. Duquesnea, S. Magnetb, C. Jama, R. Delobel: Polym. Adv. Technol. Vol. 88 (2005),p. 63

[6] M. Trifkovic1, M. Sheikhzadeh, K. Choo, S. Rohani: J. Appl. Polym. Sci. (2010). 